\title{
MORE ABOUT INSECTICIDES
}

\author{
E.K. Hartwig, D.Sc. (Pret.) \\ Ecologist, Department of Health
}

\section{OPSOMMING}

Insekdoders en sommige newe-effekte te wyte aan oplosmiddels, byvoegings, verkeerde aanwending en die vermenging van formulasies, word bespreek. Die gereelde blootstelling aan plaagdoders met 'n anticholienesterase uitwerking kan kumulatief wees. Daar moet noukeurig op enige newe-effekte wat volg op plaagdodertoediening ag geslaan word.

A $\mathrm{N}$ insecticide is a chemical used to kill insects. Insect control can also include other materials such as repellents, oils, antifeedants and attractants. Ideally, an insecticide would effectively control any target insect exposed to it and would be harmless to man and his domestic animals. It would also be readily available in necessary quantities, stable chemically, noninflammable, easily prepared and applied, noncorrosive, non-staining, and would have no undesirable odour.

If such a chemical were available, pest control would be quite easy; there would be no need to know how to prepare and store chemicals, or how to use them safely and in a way that is not objectionable. Unfortunately, there are no such ideal materials available and it is necessary to know a great many things about the chemicals which are used, especially those which are applied repeatedly. Insecticides also normally contain supplemental ingredients like solvents and synergists which can make an insecticide hazardous depending on circumstances.

Insecticide formulations possess properties not stated on labels. It is advisable to learn all we can of the insecticides in common use. Should side effects be apparent, these must be noted and followed up. "Safe" insecticides used in hospitals, homes, cafes and in agriculture can prove hazardous, particularly to some sick and old people, because of a cumulative anticholinesterase effect.

\section{POLLUTION}

A valid complaint against using insecticides is that they tend to pollute the environment. If used indiscriminately they poison the air we humans breathe, pollute our water and our food and poison many surfaces which we and our children touch daily. Animals are affected in a similar manner and their deterioration ultimately affects us. Pests also have natural enemies which help in keeping pest numbers low. Where possible, care must be taken not to kill these. Continuous use of the same insecticide can also end up in resistance building up in the pest against the particular insecticide. What can be done to remedy this?

Selective chemical control appears to be one of the most promising ways of attaining all objectives. If chemicals are applied so that they are only available to the target pest, damage to the environment is likely to be minimal.

While considerable progress has been made in finding chemicals which are biochemically selective in so far as they are highly toxic to insects and of low toxicity to man, it has proved difficult to find chemicals which are selectively toxic to a pest species and of low toxicity to its parasites and predators and other organisms in close proximity to it. Selectivity, therefore, has to be obtained in other ways.

Where a chemical has a limited persistence, considerable selectivity may be obtained by timing the 
application of the chemical so that it is applied when it will have a major effect on the pest species and a minimal effect on man, natural enemies and wildlife.

Where a chemical has systemic action in a plant or animal, it may be used in such a way that it is only available to the pest species and is therefore highly selective.

Placement of the chemical on sites favoured by the pest can confer selectivity; for example, spot treatment of known resting sites of tsetse flies and mosquitoes.

Selectivity can be increased by formulation; for example, microencapsulation of a chemical can make it selective for one particular species only and non-toxic by contact. Selectivity can also be obtained by the combination of an attractant, which is specific for the pest, with an insecticidal chemical.

Non-chemical control procedures, such as drainage of breeding sites, are most important and have to be considered when planning chemical control; the two must in fact be integrated.

The object of spraying is to keep a pest population so small that its numbers are insufficient to cause economic damage or be unhygienic. Pesticides must be applied efficiently to avoid resistance developing. Up to now, only a few pests and diseases have developed resistance to chemicals.

Sometimes resistance to one compound may be followed by resistance to other related compounds, e.g. pests resistant to one organophosphorus compound may also become resistant to other compounds in this group.

It is generally believed that the factors responsible for resistance occur naturally in the population before the insecticide is used. When the insecticide is applied over a period of years on a considerable scale the susceptible individuals are eliminated and the remaining population has the resistance factors.

Once resistance has developed its stability has been remarkable even after the removal of the selective factor. Most wild resistant strains have shown little tendency to revert to the susceptible state.

Despite the fact that resistance has made vector control very difficult in countries like the United States, some species continue to succumb to the same insecticide even though the same chemical has been used for many years.

\section{FORMULATIONS}

Industrial know-how continuously improves existing chemicals and formulations, but it may be worth our while to exploit two concepts ourselves. These are potentiation and synergism. In some cases the administration of two compounds to an insect sometimes gives an effect which is greater than the sum of the individual activities. This appears to be the case where malathion is added to fenitrothion. This general effect is termed potentiation. When one of the compounds has little or no insecticidal effect alone, it is usually termed synergism. Pyrethrum sprays are improved considerably as to biological effectiveness by the addition of piperonyl butoxide as synergist. Sulfoxide is another known synergist. When carbaryl is mixed with piperonyl butoxide, a very poisonous substance is formed.

We must discover these effects for ourselves and exploit them to the full. Private enterprise cannot be expected to disclose cases of potentiation that are known to them, because millions of dollars and several years would have to be spent on additional toxicological trials.

Unexpected effects are sometimes discovered by the user of registered chemicals where instructions given on labels are not followed categorically. A sheep farmer, for instance, dipped his dog in the same dip as his sheep and was surprised that the dip killed the dog. Similarly a fairly safe fruit fly insecticide kills birds. Endosulfant is deadly to fish, dogs and cattle.

Formulators of insecticides know of these hazards but cannot print everything on the label. They know that Diazinon changes to TEPP which is deadly to man if acid is added to the formulation. One must therefore never mix chemicals because the result could be hazardous. Also never heat an insecticide. A solvent, carbon tetrachloride will for instance change to deadly FOSGEEN gas if heated on a hot plate or open flame. Be watchful all along and make notes of everything abnormal. Discuss such cases with others and especially with experts in the particular field. Far-reaching effects could be avoided if all insecticide users would follow this practice.

\section{INSECTICIDE GROUPS}

Nowadays there is so much to learn and know that we cannot keep up with everything. We often resort to generalizations to help us cover the field about which we are expected to know the basic facts. Insects are for instance, grouped into those having a pupal stage and those without a pupal stage. Insecticides are similarly grouped into organochlorines, organophosphates, carbamates and plant derivatives, based on chemical formulae and subsequent property similarities. This does help to simplify matters. The above four groups contain all those insecticides which interest public health. The oils have been excluded because their suffocating action is straightforward.

\section{Organochlorines - OCs}

Generally the organochlorines are well-known. Examples are DDT, BHC, lindane, chlordane, dieldrin and endosulfan. Looking at the organochlorines as a whole, we note the following characteristics:

Their broad-spectrum activity against widely divergent groups of insects, including crickets, flies, beetles and wasps; certain other groups of arthropods (e.g. some mites) are susceptible to a few OCs like endosulfan; 
the comparative difficulty with wich they are biodegradable, which means that they can persist for long periods;

their comparatively low phytotoxicity hazards; their low cost.

In these characteristics lie both the strengths and the weaknesses of the organochlorines. In particular, their persistence as biologically active materials in the environment has resulted in their deleterious effects on general wildlife and their accumulation within the body tissues of many predator species, higher vertebrates and man. Fears of the contaminant and pollutant effects of the OCs have gradually forced many governments into passing legislation whereby the more persistent OCs have been progressively banned or their uses curtailed.

\section{Organophosphates - OPs}

Organophosphates are diazinon, dichlorvos, fenitrothion, TEPP, malathion, parathion and many others. Their non-persistence makes the OPs an acceptable and useful group.

OCs can be applied without fear that they will affect plant germination or subsequent growth. This is not the case with organophosphates, which carry a much greater risk of damaging the plant.

OP pesticides vary greatly in their biological properties. Some are easily hydrolysable, while others are not. Some act by contact and fumigant action, others are truly systemic. Yet others are translaminar in action and include parathion, methyl-parathion and phosphamidon, all of which are active against biting and sucking insects which are important in the public health and veterinary spheres as well as in agriculture.

Because the poisoning process entailing anticholinesterase activity in both arthropods and mammals is essentially the same, it is not surprising that those early-developed OPs which were most active against arthropods were also very toxic to humans.

\section{Carbamates}

Carbamates with carbaryl, propoxur and aldicarb as examples, have many advantages as pesticides. They are easy to formulate. Since their action is reversible they are less hazardous to man than many other pesticides and because they are readily metabolized by microorganisms, plants and animals are not likely to produce unwanted residues. Their diversity and the possibilities they possess for modification of molecular structure to increase desirable and decrease undesirable properties, make this group a potential source of many future pesticides.

The carbamates have a wide usage. Carbaryl, with a generally broad spectrum of moderate contact toxicity and reasonable persistence, is used as an alternative to DDT. Propoxur with high insecticidal contact toxicity and rapidity of action is appropriate for pests of public health and veterinary importance such as mosquitoes, biting flies and cockroaches.
The acute toxicities of carbamates to mammals vary over a wide range with carbaryl as one of the safest and aldicarb as one of the most toxic. Oral $\mathrm{LD}_{50}$,s for rats are 850 and $0,9 \mathrm{mg}$ per kilo, respectively.

Carbamates do have the advantage over organophosphorous compounds, for instance, that the rate of reactivation of inhibited cholinesterase approaches that of inactivation. Consequently, the lethal dose is much larger than that which causes the first sign of poisoning.

Based on the extensive work of the WHO Vector Control teams using carbamates for indoor spraying, it has been concluded that the early symptoms of overexposure will provide an adequate warning to stop further exposure to carbamate insecticide because symptoms will rapidly regress as soon as exposure ceases. This does not happen in the case of many of the OP compounds where symptoms may first appear and get progressively worse after exposure has ceased.

\section{Plant Derivatives}

Plant derivatives have excellent insect- and mitekilling properties. In bygone years nicotine alkaloids were used as an insecticide, but nowadays we are concentrating on the natural pyrethroids. These pyrethroids have good knock-down properties, are not poisonous to man, do not build up resistance in insects and are therefore generally employed for indoor pests. They are broken down by sunlight, which limits their outdoor use. Unavailability and their high production cost are serious limiting factors, but the white-flowered chrysanthemum plants from which pyrethroids are obtained are being grown in hothouses on an increasing scale in the Johannesburg area and this may develop into a paying proposition.

Synthetic pyrethroids have been prone to cause sensitivity in man and are therefore unsuitable for indoor use.

\section{Repellents}

Repellents developed to date have been disappointing. There have been effective ones but low sales are smothering this market. Chemicals having excellent repelling properties are known but it does not pay to develop them.

\section{CONCLUSION}

All users of insecticides should guard against overdosing, uneconomical usage, faulty and inefficient spray coverage and faulty placement of insecticide. They should also avoid contact with the diluted spray and concentrate. Keep records of spraying operations giving date of spraying, locality, insecticide used, concentration and the names of the helpers involved. Absentees must be followed up and target species must be recorded wherever possible.

Records of this nature can help pinpoint problems cropping up at later dates. Efficacy can be increased by noting consistent improvement under specific circumstances. 